\title{
Impacts of Human Resource Management on the Financial Performance of Vietnam Joint Stock Commercial Bank for Industry and Trade
}

\section{Van Dung $\mathrm{Ha}^{1}$ \\ Quoc Buu Nguyen ${ }^{2}$ \\ Hai Nam Tran ${ }^{3}$}

${ }_{1,2,3}$ Banking University Ho Chi Minh City, Vietnam.

Email:dunghv@buh.edu.vn

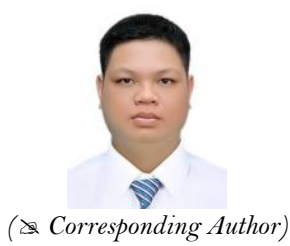

\section{Abstract}

The aim of this paper is to investigate impacts of human resource management on financial performance of Vietnam Joint Stock Commercial Bank for Industry and Trade (VietinBank). The study employs both qualitative and quantitative methods for analysis. Qualitative method is used to finalize the questionnaire while quantitative method is used to test the research hypotheses via measurement scales, descriptive analysis, EFA analysis, correlation coefficients, and linear regression model. The data is collected from 250 employees working at different branches of VietinBank in Vietnam. The results show that these 7 factors: selection, training, job description, performance appraisal, compensation system, career planning, employee participation have significant impacts on the financial performance of VietinBank.

Keywords: Human resources, Financial performance, Scales, Hypotheses, Training, Commercial Banks.

JEL Classification: J2; O15; J24.

Citation | Van Dung Ha; Quoc Buu Nguyen; Hai Nam Tran (2020). Impacts of Human Resource Management on the Financial Performance of Vietnam Joint Stock Commercial Bank for Industry and Trade. Asian Journal of Economics and Empirical Research, $7(2): 147-152$.

History:

Received: 23 March 2020

Revised: 27 April 2020

Accepted: 29 May 2020

Published: 25 June 2020

Licensed: This work is licensed under a Creative Commons

Attribution 3.0 License (c)

Publisher: Asian Online Journal Publishing Group
Acknowledgement: All authors contributed to the conception and design of the study.

Funding: This study received no specific financial support.

Competing Interests: The authors declare that they have no conflict of interests.

Transparency: The authors confirm that the manuscript is an honest, accurate, and transparent account of the study was reported; that no vital features of the study have been omitted; and that any discrepancies from the features of the study have been omit
study as planned have been explained.

Ethical: This study follows all ethical practices during writing.

\section{Contents}

1. Introduction

2. Literature Review and Research Design

3. Methodology 


\section{Contribution of this paper to the literature}

This study contributes to existing literature by investigating the impacts of human resource management on financial performance of Vietnam Joint Stock Commercial Bank for Industry and Trade.

\section{Introduction}

Banking industry has played an important role in supporting national as well as global economic growth. In Vietnam, the banking system, at the discretion of the government, has helped the country achieve its goal of growth, macroeconomic stability, and inflation control by flexible utilization of different monetary policy tools during tough economic times. In particular, from mid-2012 up to now, the macro economy of Vietnam has been gradually stabilized with a steady decrease of Consumer Price Index (CPI) towards the control level. However, in early years of the period, the economic growth encountered many obstacles such as decreased demand, high inventories, and slow economic growth. At that moment the banking industry prioritized developing and immensely implementing flexible solutions to support the growth of the economy. Noticeably, interest rates have been reduced to increase firm's access to capital sources. In addition, a series of credit programs and policies, which contribute to the economic development and social security have been effectively operated.

Up to now, the system of commercial banks in Vietnam has developed on a large scale, and become a key source of capital in the economy. By 2015, the commercial banking sector accounted for a very large proportion with total assets of $75 \%$ out of those in the whole financial system, in which, its total outstanding credit was up to 4,656 trillion VND, equal to $111 \%$ of GDP. With such a large scale, bank credits are considered as the main capital source of the economy, accounting for $40-45 \%$ of the total investment capital.

In the overall success of the industry, state-owned commercial banks have performed a key role in leading the whole sector in implementing the policies of the Government and the industry. By the end of 2015, the state-owned commercial banks sector consist of 4 banks (Agribank, BIDV, Vietinbank, Vietcombank) accounting for $45 \%$ of total assets, $50.2 \%$ of total outstanding loans and $46.3 \%$ of mobilized capital of the whole system. Over the period of 2011-2015, state-owned banks made a major contribution to the growth with an average growth rate of total assets at $13.8 \%$ per year, higher than that of the whole system at $10.3 \%$ per year, and particularly the credit grew at $17.1 \%$ per year compared to $13.5 \%$ per year of the banking industry.

Vietnam Joint Stock Commercial Bank for Industry and Trade (VietinBank) was established in 1988 and it is a state-owned commercial bank. The bank has a wide network of 155 branches, 09 member companies, 03 nonbusiness units and more than 1,000 transaction offices in 63 provinces/cities nationwide. Also, Vietinbank is the first and only the bank, which has branches in Europe: two branches in Frankfurt and Berlin - Germany. At the same time, Vietinbank has been present in Vientiane - Laos, and is actively promoting the opening of representative offices and branches in many other countries such as Myanmar, England, Poland, Czech Republic, etc. Therefore, human resource management must be taken into account as an essential part of the bank's operational management. Given that insight, this paper is conducted to evaluate how human resource management has affected financial performance of VietinBank.

\section{Literature Review and Research Design}

\subsection{Literature Reviere}

Human resources are defined as people within organizations, which should be studied in discrete aspects. In the narrow sense, they involve groups of working-age population with full physical and mental working capacity, thus equivalent to labor sources. In the broad sense, they involve those who are full 15 years of age or older. Human resources are generally considered in two dimensions, quantity and quality, so human resource development is related to both of them. However, at present, nationally and globally, the quality of human resources is the top concern so it is the main focus of human resource development activities. Human resource development is the process of improving the quality and efficiency of exploiting human resources.

Morrison (1996) proposed a model of human resource management (HRM) that included 6 components: (1) Philosophy of HRM; (2) Recruitment; (3) Job Description; (4) Socialization; (5) Training; (6) Assessment and Rewards. In particular, the Philosophy of HRM is a system of policies, points of view, assessments as well as beliefs of administrators about their employees; Socialization means that employees are empowered to participate in the planning and decision making process of their organization's general activities.

Guest (1997) proposed a model of HRM consisting of 7 components: (1) Selection; (2) Training; (3) Appraisal; (4) Rewards; (5) Job Design; (6) Involvement; (7) Status and Security. According to Pfeffer (1998) there were 7 components in HRM: (1) Ensuring job security; (2) Recruiting new employees; (3) Building autonomous and decentralized teams in decision making; (4) Setting high salary in relation to results; (5) Expanding training; (6) Reducing position gaps and barriers such as pay gap; (7) Encouraging to share information and financial results within the organization.

According to the research model of Marwat, M., and Ramay (2011) on HRM and employee performance, HRM include 07 components: Selection; Training; Performance Appraisal; Career Planning; Compensation; Employee Participation; Job description.

Qureshi, Ramay, and Marwat (2007)surveyed the impacts of factors: selection, training, performance appraisal system, compensation system, and employee participation on organizational performance. The results showed that among these factors, only the selection, training, and employee participation factors had positive impacts on organizational performance. Consistent with these findings, Singh (2004) found that there was a positive relationship between several human resource management such as recruitment, performance evaluation, training, and compensation system and employee engagement with company performance. Among these factors, only training and compensation systems have a positive impact on performance of the company and its market. Also, Wan, Ong, and Kok (2002) examined the relationship between HRM and organizational performance. The former have created a positive effect on the later. Calculation results through a regression method suggested that effective 
implementation of key HRM enhance organizational performance. On the other hand, companies concerned about improving employees' performance should stress the need for empowerment and training.

According to Qureshi, Akbar, Khan, Sheikh, and Hijazi (2010) 7 factors of human resource management have effects on financial performance of banks including selection, training, job description, performance appraisal, compensation system, job planning, and employee engagement.

\subsection{Research Model}

This study identifies different elements of human resource management that affect the financial performance of Vietnam Joint Stock Commercial Bank for Industry and Trade (Vietinbank). Based on the model of Qureshi et al. (2010) the research paper has selected the following factors: selection, training, job description, performance appraisal, compensation system, job planning, and employee participation.

The expected signs of coefficients or the directions of impacts are also shown in the proposed model in Figure 1.

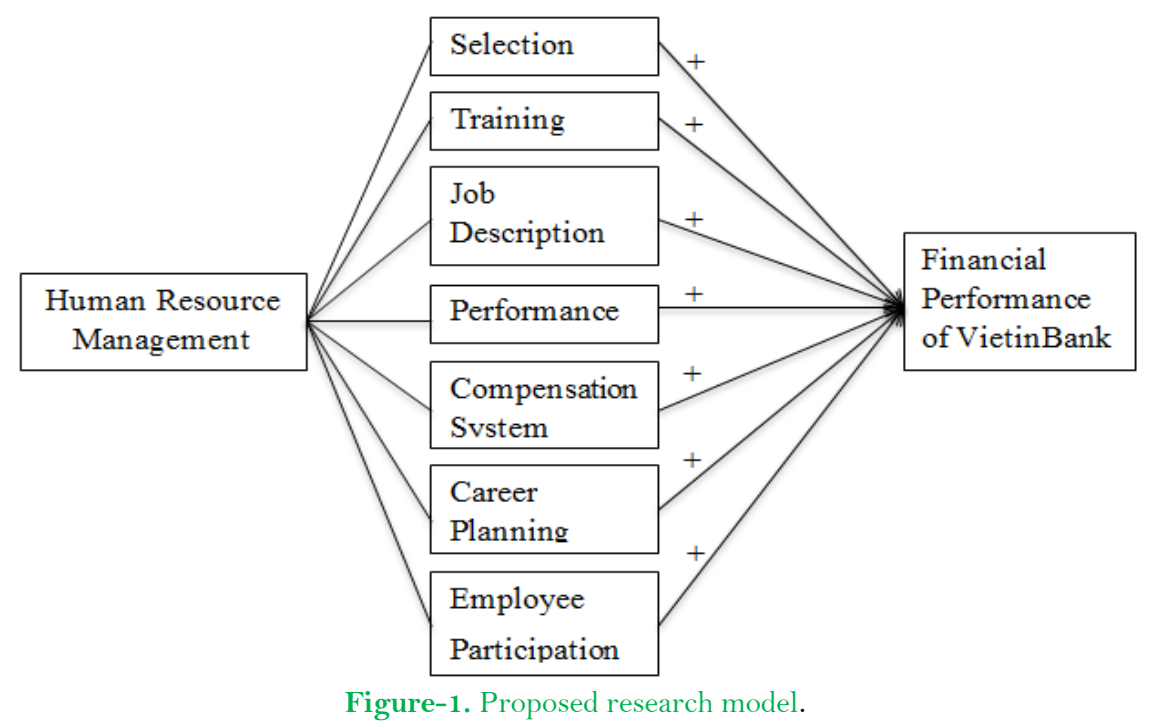

\section{Methodology}

The quantitative method employs the interview techniques by emails and questionnaires. The sample of 250 employees is randomly selected in VietinBank's system. The collected data is processed by the software SPSS 20, then Cronbach's Alpha test will be used for assessments on the reliability of scales, also Barlett and KMO tests are adopted for exploring factor analysis (EFA). Meanwhile, regression analysis will be used to measure the impacts of human resource management.

\section{Research Results}

\subsection{Cronbach's Alpha analysis}

After the first Cronbach's Alpha analysis, the results in Table 1 show that Cronbach's Alpha equal to 0.588. However, the correlation value of the total variable of FP4 and FP5 are -0,116; 0.060 less than 0.3 (invalid for the reliability analysis). Therefore, the author removes the FP4 and FP5 variables of the Financial Performance factor and performs the second reliability test. After that, the researcher obtains a Cronbach's Alpha coefficient of 0.817 (greater than 0.6, valid for the reliability analysis) and all correlation coefficients of variables are greater than 0.3. Therefore, the variables FP1, FP2, FP3 which belong to the Financial Performance group are suitable to be included in the next analysis step.

Table-1. Cronbach's Alpha analysis results.

\begin{tabular}{|c|c|c|c|}
\hline \multirow[t]{2}{*}{ Factor } & \multirow{2}{*}{$\begin{array}{c}\text { Before analyzing Cronbach's } \\
\text { Alpha } \\
\text { Number of variables at first }\end{array}$} & \multicolumn{2}{|c|}{$\begin{array}{c}\text { After analyzing } \\
\text { Cronbach's Alpha }\end{array}$} \\
\hline & & $\begin{array}{c}\text { coefficient } \\
\text { Cronbach's Alpha }\end{array}$ & Number of variables \\
\hline Selection & 4 & 0.936 & 4 \\
\hline Training & 6 & .926 & 4 (remove T5, T6) \\
\hline Job description & 4 & 0.830 & 3 (remove JD4) \\
\hline Performance Appraisal & 7 & 0.825 & 5 (remove PA6, PA7) \\
\hline Compensation System & 5 & 0.925 & $4($ remove $\mathrm{CS} 5)$ \\
\hline Career Planning & 7 & 0.829 & 4 (remove $\mathrm{CP} 5, \mathrm{CP} 6, \mathrm{CP} 7)$ \\
\hline Employee Participation & 3 & 0.764 & 3 \\
\hline Financial Performance & 5 & 0.817 & 3 (remove FP4, FP5) \\
\hline
\end{tabular}

After the analysis and evaluation of the reliability of the scales, it is concluded that 41 scales (including variables of dependent and independent factors) are all eligible, except for the T5, T6 (of Training factors), JD4 (of Job description factor), PA6, PA7 (of Performance Appraisal factors), CS5 (of Compensation System factors), CP5, $\mathrm{CP} 6, \mathrm{CP} 7$ (of Career Planning factors), FP4, FP5 (of Financial Performance factors). All of the remaining scales (30 scales) are, therefore, included in the analysis of the following sections. 


\subsection{Results of Exploratory Factor Analysis (EFA)}

4.2.1. Exploratory Factor Analysis of Independent Variables

All 28 variables belonging to independent factors that satisfied Cronbach's Alpha reliability analysis are included in the exploratory factor analysis (EFA). The EFA's mission is to explore the structure of the factors affecting financial performance through 7 factors: S (Selection), T (Training), JD (Job description), PA (Performance Appraisal), CS (Compensation System), CP (Career Planning), and EP (Employee Participation). After ensuring proper implementation of the EFA process, these factors will be tested for data cleaning. Performing the EFA analysis for a total of 28 variables of the independent factors affecting financial performance, the study obtains the following results in Table 2 .

Table-2. KMO test of variables with independent factors.

\begin{tabular}{|c|c|c|}
\hline \multicolumn{2}{|l|}{ Criteria } & value \\
\hline \multicolumn{2}{|l|}{ KMO } & 0.643 \\
\hline \multirow[t]{3}{*}{ Bartlett's test of sphericity } & Approx. Chi-Square & 6720.983 \\
\hline & $\mathrm{df}$ & 351 \\
\hline & Sig. & 0.000 \\
\hline
\end{tabular}

After the factor analysis of variables of independent factors, the paper obtains KMO coefficient $=0.643$ with Sig. $=0.000$. This result shows the appropriateness of exploratory factor. The Chi-Square statistic of Bartlett's test is 6,720.983 with significant level of 0.000 . At the same time, the analysis of variance shows that the average variance extracted reaches $75.038 \%$, this value is quite high. So it could be said that $75.038 \%$ of variation is explained by 7 factors, from which the scales are built and accepted. The stopping point when extracting factors from the seventh factor group with eigenvalue value is 1.361, greater than 1 (which ensures the inclusion of variables of these factors into the following analysis steps. Variables are classified into 7 groups of factors).

Table-3. Rotated component matrix.

\begin{tabular}{|c|c|c|c|c|c|c|c|}
\hline & \multicolumn{7}{|c|}{ Component } \\
\hline & 1 & 2 & 3 & 4 & 5 & 6 & 7 \\
\hline S3 & 0.974 & & & & & & \\
\hline $\mathrm{S} 4$ & 0.974 & & & & & & \\
\hline $\mathrm{S} 1$ & 0.974 & & & & & & \\
\hline $\mathrm{S} 2$ & 0.691 & & & & & & \\
\hline T3 & & 0.974 & & & & & \\
\hline $\mathrm{T} 2$ & & 0.969 & & & & & \\
\hline $\mathrm{T} 4$ & & 0.949 & & & & & \\
\hline $\mathrm{T} 1$ & & 0.710 & & & & & \\
\hline CS3 & & & 0.931 & & & & \\
\hline $\mathrm{CS} 4$ & & & 0.929 & & & & \\
\hline $\mathrm{CS} 2$ & & & 0.849 & & & & \\
\hline $\mathrm{CS} 1$ & & & 0.800 & & & & \\
\hline PA3 & & & & 0.860 & & & \\
\hline PA4 & & & & 0.834 & & & \\
\hline PA2 & & & & 0.779 & & & \\
\hline $\mathrm{PA} 1$ & & & & 0.743 & & & \\
\hline$\overline{\mathrm{PA} 5}$ & & & & 0.609 & & & \\
\hline $\mathrm{CP} 3$ & & & & & 0.855 & & \\
\hline $\mathrm{CP} 2$ & & & & & 0.804 & & \\
\hline $\mathrm{CP} 4$ & & & & & 0.801 & & \\
\hline $\mathrm{CP} 1$ & & & & & 0.760 & & \\
\hline JD3 & & & & & & 0.885 & \\
\hline JD2 & & & & & & 0.858 & \\
\hline JD1 & & & & & & 0.814 & \\
\hline $\mathrm{EP} 1$ & & & & & & & 0.832 \\
\hline $\mathrm{EP} 2$ & & & & & & & 0.778 \\
\hline EP3 & & & & & & & 0.706 \\
\hline
\end{tabular}

The rotated component matrix results (in Table 3) indicate the number of coefficients. They all met the requirements (the factor loadings are greater than 0.5) and are arranged into 7 separate groups of factors, including S (Selection), T (Training), JD (Job description), PA (Performance Appraisal), CS (Compensation System), CP (Career Planning), EP (Employee Participation).

\subsubsection{EFA of Financial Performance}

The scales of financial performance are built to survey financial performance. It included 3 variables $\mathrm{FP} 1, \mathrm{FP} 2$, FP3 which are put into the EFA factor analysis.

Table-4. EFA analysis results.

\begin{tabular}{|c|c|c|}
\hline \multicolumn{2}{|l|}{ Criteria } & value \\
\hline \multicolumn{2}{|l|}{ KMO } & 0.710 \\
\hline \multirow[t]{3}{*}{ Bartlett's test of sphericity } & Approx. Chi-Square & 268.807 \\
\hline & $\mathrm{df}$ & 3 \\
\hline & Sig. & 0.000 \\
\hline
\end{tabular}


The Table 4 indicates that the KMO is 0.710 . This result shows the appropriateness of exploratory factor. The Chi-Square statistic of Bartlett's test is worth 268.807 with significance $=0.000$. The KMO test result, therefore, is proven to be completely statistically significant at the level of $5 \%$.

Along with that, the factor loadings of the component variables $\mathrm{FP} 1, \mathrm{FP} 2, \mathrm{FP} 3$ are respectively 0.850 ; 0.883 ; 0.841 (all greater than 0.5), which implied that the component variables of the factor financial performance are valid for the data analysis.

In general, the EFA of Financial Performance confirms appropriateness of dependent variable so that the paper could perform a regression analysis, in which the factor Financial Performance is assigned as a dependent variable.

\subsection{Regression Analysis}

This regression analysis aimed to determine the degree of influence of independent factors on FP factor (Financial Performance).

The results from linear regression indicate that the total significant value of independent factors is less than $5 \%$, which means that these 7 factors: S (Selection), T (Training), JD (Job description), PA (Performance Appraisal), CS (Compensation System), CP (Career Planning), EP (Employee Participation) significantly affect financial performance.

Consequently, the regression equation (according to the non-standardized coefficient) of the model showing the effects of S (Selection), T (Training), JD (Job description), PA (Performance Appraisal), CS (Compensation System), $\mathrm{CP}$ (Career Planning), EP (Employee Participation) is presented as follows:

\section{$\mathrm{FP}=-0.754+0.150 * \mathrm{~S}+0.205 * \mathrm{~T}+0.120 * \mathrm{JD}+0.078 * \mathrm{PA}+0.135 * \mathrm{CS}+0.110 * \mathrm{CP}+0.350 * \mathrm{EP}+\mathrm{e}_{\mathrm{i}}$}

The most influential factor on the financial performance is the Employee Participation (the beta is 0.350). The higher employee participation is, the better is finance performance (one additional unit of the EP leads to an increase of 0.350 units of the FP). The second large is $\mathrm{T}$ (the beta is 0.205). The FP increased 0.205 units for every increase of one unit in the T. The next one is the S factor, then come CS, JD, CP, and PA.

Based on the standardized beta, the level of impact of independent factors on financial performance is given in Table 5 .

\begin{tabular}{l|c}
\multicolumn{2}{c}{ Table-5. Degree of impact of factors. } \\
\hline Factor & Level of impact (1- strongest ) \\
\hline Employee participation & 1 \\
\hline Training & 2 \\
\hline Selection & 3 \\
\hline Compensation System & 4 \\
\hline Job description & 5 \\
\hline Career Planning & 6 \\
\hline Performance Appraisal & 7 \\
\hline
\end{tabular}

It could be seen that, as for Vietnam Joint Stock Commercial Bank for Industry and Trade, the level of impact, in order from high to low is as follows: Employee Participation, Training, Selection, Compensation System, Job description, Career Planning, and Performance Appraisal.

\section{Conclusion}

Based on the previous research and theories related to analyzing the impact of human resource management on financial performance, the researcher synthesized and proposed a research model including independent factors: $\mathrm{S}$ (Selection), T (Training), JD (Job Description), PA (Performance Appraisal), CS (Compensation Scheme), CP (Career Planning), and EP (Employee Participation) while FP (Financial Performance) is the dependent variable.

The paper conducts qualitative research to correct and supplement errors if any and then proceeded to create a survey form and undertook an official investigation to collect opinions of employees at VietinBank's branches. After that, a review of the collected questionnaires to see whether they are appropriate or not is held, and followed by a statistical process in the shape of a preliminary step towards the analysis.

With the collected database, the author ran the SPSS software to produce information statistics of the surveyed individual subjects as well as performed the main task of analyzing and evaluating the impact of human resource management on the financial performance of Vietnam Joint Stock Commercial Bank for Industry and Trade.

After presenting the fundamental theories about human resources, human resource management and especially domestic and foreign studies in detecting and analyzing influence factors of human resource management on improving financial performance, the researcher proposed 7 main factors of human resource management affecting FP (Financial efficiency), namely: S (Selection), T (Training), JD (Job description), PA (Performance Appraisal), CS (Compensation System), CP (Career Planning), EP (Employee Participation). The researcher then conducted an analysis to evaluate the reliability of the scales. The results showed that 41 analyzed scales (including the scales of dependent and independent factors) all met the requirements, except for the scales T5, T6 (Training factors), JD4 (Job description factor), PA6 and PA7 (Performance Appraisal factors), CS5 (Compensation System factor), CP5, $\mathrm{CP} 6, \mathrm{CP} 7$ (Career Planning factors), FP4, FP5 (Financial Performance factors). These invalid scales are removed from the next analysis. The results of factor analysis showed that all variables belonging to independent factors met the analysis requirements (the factor loadings are greater than 0.5). The total of 28 component factors are arranged into 7 separate groups of independent variables, namely, S, T, JD, PA, CS, CP, and EP.

The results of the linear regression model showed that all 7 independent variables have positive impacts on financial performance of VietinBank. It means that the effects of independent variables on financial performance of Vietinbank are as expectation.

\section{References}

Guest, D. E. (1997). Human resource management and performance: A review and research agenda. International Journal of Human Resource Management, 8(3), 263-276.Available at: https://doi.org/10.1080/095851997341630. 
Marwat, Z. A., M., Q. T., \& Ramay, M. I. (2011). Impact of human resource management (HRM) practices on employees performance. Retrieved
https://www.academia.edu/770358/IMPACT_OF_HUMAN_RESOURCE_MANAGEMENT_HRM_PRACTICES_ON_EMPL Retrieved
https://www.academia.edu/770358/IMPACT_OF_HUMAN_RESOURCE_MANAGEMENT_HRM_PRACTICES_ON_EMPL OYEES_PERFORMANCE. [Accessed 16/11/2019].

Morrison, E. W. (1996). Organizational citizenship behavior as a critical link between HRM practices and service quality. Human Resource Management, 35(4), 493-5 12.Available at: https://doi.org/10.1002/(sici)1099-050x(199624)35:4<493::aid-hrm4>3.0.co;2-r.

Pfeffer, J. (1998). The real keys to high performance. Leader to Leader, 8(1), 23-29.Available at: https://doi.org/10.1002/lt1.40619980809.

Qureshi, T. M., Akbar, A., Khan, M. A., Sheikh, R. A., \& Hijazi, S. T. (2010). Do human resource management practices have an impact on financial performance of banks? African Journal of Business Management, 4(7), 1281-1288.

Qureshi, T. M., Ramay, M. I., \& Marwat, Z., A. (2007). Impact of human resource management (HRM) practices on employees performance. Islamabad: Muhammad Ali Jinnah University.

Singh, K. (2004). Impact of HR practices on perceived firm performance in India. Asia Pacific Journal of Human Resources, 42(3), 301317.Available at: https://doi.org/10.1177/1038411104048170.

Wan, D., Ong, C. H., \& Kok, V. (2002). Strategic human resource management and organizational performance in Singapore. Compensation $\mathbb{E}^{\circ}$ Benefits Review, 34(4), 33-42.Available at: https://doi.org/10.1177/0886368702034004006. 